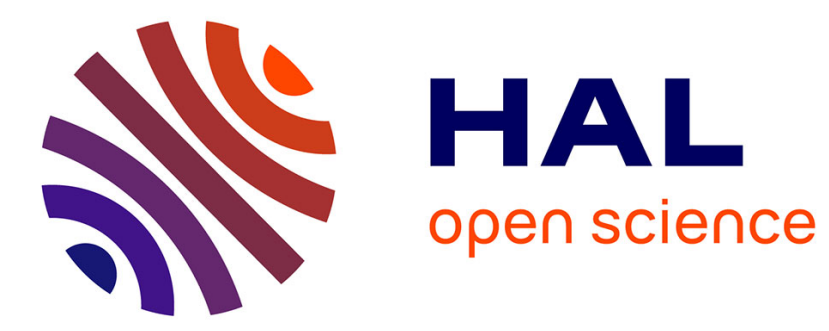

\title{
How can tsetse population genetics contribute to African trypanosomiasis control?
}

Philippe Solano, Sophie Ravel, Thierry de Meeûs

\section{To cite this version:}

Philippe Solano, Sophie Ravel, Thierry de Meeûs. How can tsetse population genetics contribute to African trypanosomiasis control?. Trends in Parasitology, 2010, 26 (5), pp.255-263. 10.1016/j.pt.2010.02.006 . ird-01224447

\section{HAL Id: ird-01224447 \\ https://hal.ird.fr/ird-01224447}

Submitted on 4 Nov 2015

HAL is a multi-disciplinary open access archive for the deposit and dissemination of scientific research documents, whether they are published or not. The documents may come from teaching and research institutions in France or abroad, or from public or private research centers.
L'archive ouverte pluridisciplinaire HAL, est destinée au dépôt et à la diffusion de documents scientifiques de niveau recherche, publiés ou non, émanant des établissements d'enseignement et de recherche français ou étrangers, des laboratoires publics ou privés. 


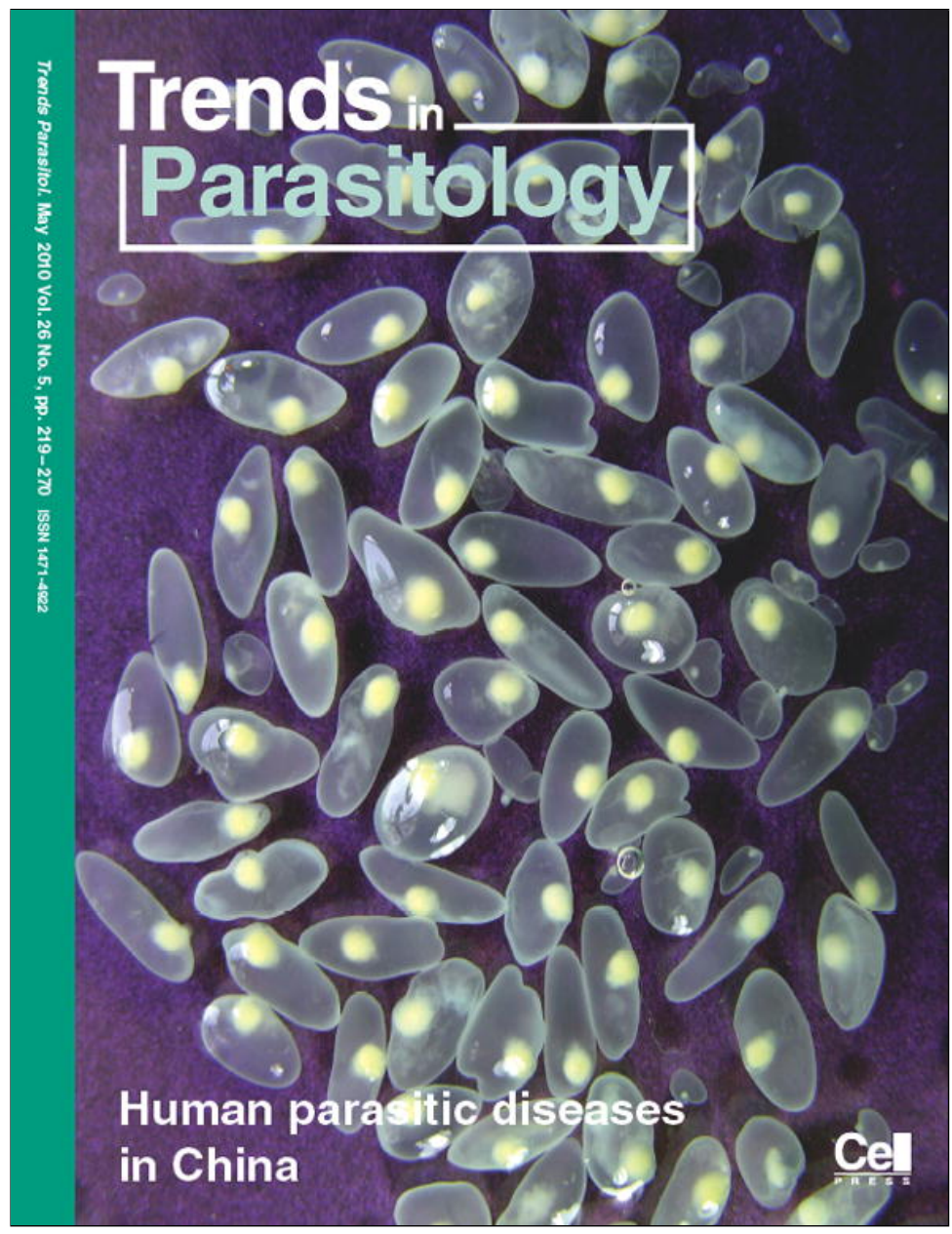

This article appeared in a journal published by Elsevier. The attached copy is furnished to the author for internal non-commercial research and education use, including for instruction at the authors institution and sharing with colleagues.

Other uses, including reproduction and distribution, or selling or licensing copies, or posting to personal, institutional or third party websites are prohibited.

In most cases authors are permitted to post their version of the article (e.g. in Word or Tex form) to their personal website or institutional repository. Authors requiring further information regarding Elsevier's archiving and manuscript policies are encouraged to visit:

http://www.elsevier.com/copyright 


\title{
How can tsetse population genetics contribute to African trypanosomiasis control?
}

\author{
Philippe Solano ${ }^{1}$, Sophie Ravel ${ }^{2}$ and Thierry de Meeûs ${ }^{1,3}$ \\ ${ }^{1}$ Institut de Recherche pour le Développement (IRD)/Centre International de Recherche pour I'Elevage en zones Subhumides \\ (CIRDES), IRD UMR 177, CIRDES 01 BP 454 Bobo-Dioulasso 01, Burkina Faso \\ ${ }^{2}$ IRD UMR 177, Laboratoire de Recherche et de Contrôle des Trypanosomoses IRD-CIRAD (Centre de coopération Internationale en \\ Recherche Agronomique pour le Développement), Campus International de Baillarguet, 34398 Montpellier cedex 5, France \\ ${ }^{3}$ Centre National de la Recherche Scientifique (CNRS), Délégation Languedoc-Roussillon, 1919, route de Mende -34293 \\ Montpellier cedex 5, France
}

In sub-Saharan Africa, tsetse transmitted Trypanosomiases have an enormous impact on human health and economic development. Both the World Health Organisation and African countries through the Pan African Tsetse and Trypanosomiasis Eradication Campaign (PATTEC) have recently asserted their determination to rid the sub-continent of these diseases, and it is increasingly recognised that vector control should play an important role. This review mainly focuses on population genetics of tsetse of the palpalis group, the main vectors of sleeping sickness, and reports recent results on tsetse population structure and on measures of gene flow between populations. Implications of these studies for large-scale tsetse control programmes being undertaken in West Africa are important, particularly regarding control strategies (suppression or eradication).

\section{Programmes for elimination of Trypanosomiases in Africa}

Tsetse flies (Diptera: Glossinidae) occur over much of subSaharan Africa, in an area approaching 10 million $\mathrm{km}^{2}$. The trypanosomes they transmit affect human welfare, both directly, through the chronic (owing to Trypanosoma brucei gambiense) and acute (T. brucei rhodesiense) forms of sleeping sickness (also known as human African trypanosomiasis, HAT), and, indirectly, through the wasting diseases of livestock (animal African trypanosomiases, AAT). It has been estimated [1] that economic benefits to Africa from the eradication of tsetse could reach US $\$ 4.5$ billion per year.

In the early part of the 20th century, hundreds of thousands of cases of HAT occurred in sub-Saharan Africa (reviewed in Ref. [2]). Systematic screening, treatment and follow-up of millions of individuals in the whole continent led to transmission coming to a near halt by the $1960 \mathrm{~s}$. Over time, the disease slowly returned, and, by the $1990 \mathrm{~s}$, flare-ups were observed throughout former endemic areas, some of which returned to prevalences observed at the beginning of the century. To combat the human health costs of trypanosomiasis, the World Health Organisation

E-mail addresses: solano@ird.bf, ssolano@free.fr
(WHO) has recently launched a HAT elimination programme. HAT due to T. b. gambiense currently constitutes 97\% of the total HAT cases [3], and is transmitted almost exclusively by two vector species of the palpalis group, $G$. fuscipes s.l. and G. palpalis s.l.. Recently, the African Union (AU) has launched the Pan African Tsetse and Trypanosomiasis Eradication Campaign (PATTEC), a continentwide initiative that focuses on the progressive elimination of discrete tsetse-infested areas. This vector control programme aims to use a variety of methods depending on fly species, agro-ecology and the capacity of local and national tsetse control agencies [4].

\section{Why focus on vector control?}

Despite the existence of various drugs effective against AAT (curative and preventive trypanocides), chemotherapy and/ or chemoprophylaxis alone cannot eliminate the problem of trypanosomiasis: it is not only impossible to treat all wild and domestic hosts but there is also an increasing problem with drug resistance and little prospect of new drugs being developed (for AAT or for HAT). In addition, recent $T . b$. gambiense genetic data suggest that many trypanosome strains escape from direct observations during medical surveys [5]. Vector control strategies offer an excellent partner to case detection and treatment because (i) reducing vector density can rapidly halt human trypanosomiasis transmission [6,7] and (ii) technologies for vector control already exist, although they are seldom used in practice to control the gambiense form of disease. In addition, vector control remains the only available strategy capable of protecting human individuals from acquiring infection. Finally, tsetse have never been reported to show any resistance to insecticide. Thus, we are strongly convinced that vector control should represent an important complementary strategy to case detection and chemotherapy, which has remained the main strategy for HAT control.

Human population growth in sub-Saharan Africa [8] and global warming [9] (with their associated impact on agro-ecology) preliminarily data suggest that the habitats where tsetse populations can thrive will be reduced, although (worryingly) palpalis group tsetse show abilities to adapt to urban habitats (reviewed in Ref. [10]), where 
they can cause severe outbreaks, such as the recent one in Kinshasa [11].

Mating patterns, population size and migration represent the key factors determining the genetic structure of population and, ultimately, the evolutionary biology of species [12-14]. Estimating these parameters is a prerequisite to any control campaign if it is to be sustainable and represents a major task in population genetics $[15,16]$. To achieve this, labour-intensive mark-release-recapture (MRR) studies were undertaken. Such techniques are difficult to apply, particularly for organisms such as parasites and vectors $[12,14]$. The advent of molecular markers has proven to be very useful in that they allow key parameters to be identified, either as a complement to MRR studies or without MRR when impossible to undertake.

This review aims to summarise the 'state of the art' of tsetse population genetics of the palpalis group, its importance and potential for tsetse and trypanosomiasis control. Previous reviews focused mainly on tsetse of the morsitans group, which are more involved in animal trypanosomiases [17], or were written at a time when few population genetic studies had been conducted, and there was not such an international context of elimination [18]. Since 2005, more studies of tsetse genetics have been completed with an emphasis on species of the palpalis group because they are the main vectors of gambiense HAT and also, increasingly, of AAT in places where human densities have recently increased $[19,20]$.

\section{Tsetse are unique vectors}

Tsetse are unique among medically important vectors, with a series of biological and demographic characteristics that (should) make them vulnerable to available control methods (Box 1).
Under current classifications, the 31 currently recognized species and subspecies of the sole Glossina genus are placed into three species groups, which have been given subgeneric status (recently reviewed in Ref. [21]): fusca group (subgenus Austenina), palpalis group (subgenus Nemorhina) and morsitans group (subgenus Glossina). Species of the fusca group typically occur in lowland rainforests of West and Central Africa. Species of the palpalis group are called 'riverine' or 'lacustrine' and are more usually associated with coastal (including mangrove) habitats, degraded forests of West Africa and riverine vegetation, but some also extend into savannah regions along river systems. Species of the morsitans group, main vectors of AAT, are associated primarily with drier savannahs.

\section{The taxonomy of G. palpalis palpalis and G. p. gambiensis}

Glossina palpalis sensu lato comprises two vicariant subspecies that are separated from each other by an 'exclusion belt' [27]. G. p. gambiensis is a riverine fly that lives in the riparian vegetation along the rivers of humid savannahs of West Africa, from Senegal to Benin (Figure 1). It can, however, be found in areas where annual rainfall is low $(<600 \mathrm{~mm})$, provided that high humidity is combined with host availability (e.g. in the typical Niayes of Senegal) (reviewed in Ref. [21]). G. p. gambiensis is also found in the mangrove swamps of Guinea [28]. By contrast, G. p. palpalis lives in degraded forest habitats from Liberia to Angola and along the coasts. Thus, it is much less riverine than the other subspecies. According to Challier et al. [27], there are five countries in which both subspecies occur, from West to East: Guinea, Sierra Leone, Ivory Coast, Ghana and Togo (Figure 1). Both subspecies show an

\section{Box 1. Tsetse, a unique vector}

Tsetse (Diptera: Glossinidae) display a series of biological and demographic characteristics that make them unique among medically important vectors. Their life cycle is particularly unusual as they do not lay eggs. Instead, a single larva develops within the female uterus. The larva feeds from the uterine glands of the mother ('adenotrophic viviparity') and is larviposited as a mature larva (3rd instar, L3) into humid soil. The larva then quickly burrows into the soil surface, where it pupates. The adult emerges 20-80 days later (Figure I), depending on temperature and humidity (pupal development does not succeed below $17{ }^{\circ} \mathrm{C}$ and above $32{ }^{\circ} \mathrm{C}$ ) [21]. Thus, each female produces only one offspring at a time, and, in Nature, could produce no more than 3-5 offspring during its total life (which lasts around 3 months for females, 2 months for males, taking into account predation and mortality). As a result, the intrinsic rate of tsetse population growth tends to be low, with the maximum rate of population increase being no more than $10-15$ times per year $[6,22]$. This means that even a small increase in average daily mortality rate can cause a population to decline in number. However, controversies remain as to whether such a decline can lead to eradication, particularly for tsetse of the palpalis group, which are able to survive at low densities. Newly emerging flies have few resources and tend to be less discriminatory about the host for their first bloodmeal than for subsequent feeds. Host preference has been reported (in experimental conditions) to be influenced by the first host encountered for a bloodmeal, although this is altered by starvation [23]. Laboratory observations show that, in contrast to long-standing assumptions, tsetse can be infected at any time of their life with trypanosomes, including T. brucei [24-26], if they have been starved. Both females and males feed from vertebrate blood and therefore are both vectors. The female is fecunded at its first mating, very soon after emergence, which makes them potentially ideal candidates for genetic control methods such as the sterile insect technique. Finally, no insecticide resistance has ever been reported so far for tsetse..

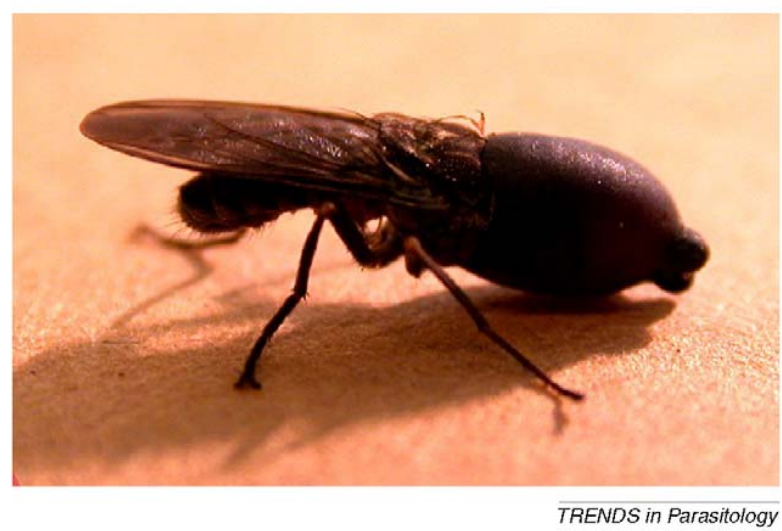

Figure I. A young tsetse adult recently emerged after having spent around month in the puparium, illustrating the particular reproductive biology of this insect group. Picture: CIRAD-IRD, UMR 17. 


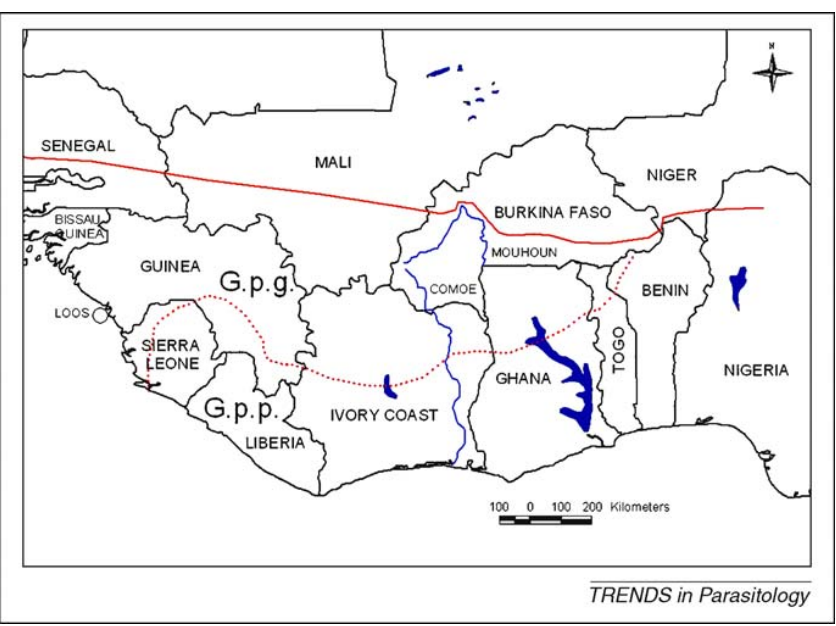

Figure 1. Geographical distribution of Glossina palpalis s.l. in West Africa. Th unbroken red line shows the estimated G. p. gambiensis northern distribution limit, the dotted red line shows the approximate limit between G. p. gambiensis and G. p. palpalis reported by Challier et al. [27]. Some of the locations most cited in the manuscript are indicated (Loos islands in Guinea; Mouhound and Comoe river in Burkina Faso).

opportunistic feeding behaviour and local genetic structuring $[29,30]$, with some exceptions found in G. p. gambiensis in mangrove ecosystems where continental populations were found panmictic over wide areas [28]. The important differences in ecology of these subspecies, combined with the occurrence of male sterility of laboratory reared hybrids [31], as well as the recent design of a G. p. gambiensis/G. p. palpalis diagnostic ITS1 PCR [32], makes us think that these two subspecies are truly different taxa that should be elevated to species rank, with a direct benefit in simplifying the puzzling taxonomy of this group of insects. Even within $G$. p. palpalis there are indications of species complexes [33,34]. Having such information is also of crucial importance regarding tsetse control strategies and methods, in particular (but not only) those involving a genetic component such as the Sterile Insect Technique (SIT). Different species are also expected to show different responses to any given stimulus, such as vision, olfaction or behaviour [35], which can thus have consequences on tsetse control techniques.

\section{Population genetics}

\section{First things first: the sampling strategy}

For population genetics tools to provide the most accurate inferences, investigators must be able to sample individuals at the smallest possible scale (i.e. at a resolution less than the geographical area occupied by a single deme). However, most sampling has failed to do this, as suggested by the numerous cases where significant heterozygote deficits (positive $F_{\text {IS }}$; Box 2 ) were found. In dioecious, random-mating populations (such as tsetse) $F_{\text {IS }}=-1 /$ $(1+2 N)$ [36], where $N$ is the census population size. Hence, random mating should even lead to a negative $F_{\text {IS. }}$ Consequently, finding a positive $F_{\text {Is }}$ affecting all loci is likely to be the consequence of a Wahlund effect (Box 2). Positive $F_{\text {IS }}$ values have indeed been reported in several species of tsetse in several habitat types [28-30,38,40-44]. Some of these studies used the Bonferroni correction that probably

\section{Box 2. Glossary and terms}

A population bottleneck corresponds to an abrupt drop in population size that can leave a genetic signature in populations and, when detected, can provide a probable post bottleneck $N_{e}$ [28].

A deme is the demographic unit grouping individuals that share the same regulation processes, i.e. synonymous to subpopulation.

Dioecious organisms: synonymous to gonochoric, it means that the species are subdivided into males and females (opposite to monoecious).

A discrete isotrope random walk (same probability of going upstream or downstream one distance unit at each time unit) was used to model Glossina palpalis gambiensis dispersal in savannah in Burkina Faso. It can be regarded as the simplest individual-based model of dispersal in one dimension. The assumptions of the mode are that during one time unit a single fly will travel exactly one unit length either to the right or left with equal probability (see Ref. [37] for details and references).

The effective population size, $\boldsymbol{N}_{\boldsymbol{e}}$ is a useful (yet complex) concept in population genetics. It measures the speed at which genetic diversity is lost by genetic drift. It corresponds approximately to the number of reproducing adults (see Ref. [14] for a more detailed definition). It can be estimated with different methods such as correlation between alleles within individuals, between loci or using temporal allele frequency variation.

Homoplasy: a phenomenon describing the identity between two alleles that do not share a common ancestry, which are then said identical by state.

Isolation by distance occurs when reproductive dispersal is constrained by distance and produces a continuous change in allelic frequencies, the nearest geographically is the closest genetically. Such a pattern allows very powerful inferences on neighbourhood size and hence infers density or dispersal of individuals ([38] and Figure 2).

Linkage disequilibrium between loci (LD) is sensitive to demographic parameters and reproductive systems. In random mating populations, as expected for tsetse flies (within true demes at least), some methods exist allowing $N_{e}$ estimation using LD estimation [28].

Wright's fixation indices or F-statistics (recently reviewed in Ref. [14]) allows measurement of the relative partitioning of genetic information within individuals, between them and across subsamples. These statistics are useful in the assessment of the relative contribution of individual behaviour (reproductive system), subpopulation size and migration, in a standardised way (comparable across studies). Initially designed to describe an Island model of population structure with three levels (individual, subpopulation and total population), three such statistics were described: $F_{I S}$ is a measure of inbreeding owing to deviations from the panmictic mode within subpopulations; $F_{\mathrm{ST}}$ is a measure of inbreeding that is as a result of subdivision; and $F_{\mathrm{IT}}$ is a measure of inbreeding coming from the two previous factors. From there, $F_{I S}$ is a standardised measure of local deviations from panmixia, corrected for the effect of small subpopulation size, $F_{\mathrm{ST}}$ is a measure of population differentiation (Wahlund effect) and $F_{\mathrm{IT}}$ is the result of the two previous phenomena. $F_{\mathrm{IS}}$ varies from -1 (one class of heterozygote) to +1 (all individuals are homozygous) and is null under panmixia, $F_{\mathrm{ST}}$ varies from 0 (no influence of subdivision) to +1 (all subpopulations fixed for one or the other allele) and $F_{\mathrm{IT}}$ varies from -1 to +1 . It is noteworthy that, when mutation rate is important, or when the reproductive system allows more alleles to be maintained in subpopulations than the number of subpopulations (or subsamples) itself, then $F_{\mathrm{ST}}$ does not totally reflect subdivision as its maximum possible value $F_{\mathrm{ST} \text { max }}<1$. In such a case, a corrected value can be useful and a proxy to the real $F_{\mathrm{ST}}$ would be $F_{\mathrm{ST}}{ }^{\prime}=F_{\mathrm{ST}} / F_{\mathrm{ST} \text { max }}$. More than three levels can be handled with the same type of approach (see Ref. [39] and references therein). As described elsewhere [14], these parameters are useful tools for ecological inferences such as reproductive strategy, migration rate $m$ and effective population size $N_{e}$. 


\section{Box 3. The caveats of Bonferroni correction}

When a series of $k$ tests has to be taken into account and a global decision to be made, several procedures can be undertaken, depending on what is specifically looked for and what is available. Indeed, increasing the number of tests increases the possibility to randomly find a significant one: if 100 tests are undertaken, then five tests are expected to be significant under $H_{0}$ at level $\alpha=0.05$ (by definition). Thus, something must be done to avoid this problem. There are two types of situations that must be distinguished according to the question asked. The first is: which tests are significant among the $k$ tests? The second is: is the $k$ test series significant as a whole? For the first question, only makeshift procedures (i.e. without clear theoretical justifications) are available, the philosophy of which is to reduce the level of significance in a way that will hopefully exclude all false positives. The most popular procedure is the so-called Bonferroni procedure and its sequential derivative [45] where the lowest $P$-value of the $k$ tests series is multiplied by $k$, the second lowest by $k-1$, etc. This procedure is highly conservative. This is particularly true for frequency data tests such as those classically used in population genetics. Indeed, in such type of data, lowest $P$-values are seriously bound by sample sizes, degree of polymorphism and number of randomisations. For instance, if $k=40$, the minimum $P$-value required to be significant will have to be under or equal to 0.00125 , a value that will most of the time lie far beyond the reach. In that case, only most powerful tests must be kept (e.g. those where no allele has a frequency above 0.8 or 0.9 and for which sample size is $>10$ ). For the second question, the devastating Bonferroni procedure should always be avoided. Two subsituations can arise. If a global test exists, such as for the $F_{\mathrm{IS}}$ test of significance as implemented in Fstat [46] or Genepop [47], then this test must be undertaken. If a global test does not exist (e.g. linkage disequilibrium test across loci pairs and subsamples) then a unilateral exact binomial test, with mean $\alpha$ (e.g. 0.05$)$, number of trials $k$, and number of success $k^{\prime}$ (number of significant tests at level $\alpha)$ should be preferred. Note that a more powerful approach, the generalised binomial procedure, was recently released [48].

obscured many significant differences [42-44] (Box 3). Furthermore, each time that studies have been undertaken to detect population substructure it has indeed been found, either as a cryptic structure (the origin of which thus remains to be fully elucidated) $[29,30]$ or because of an isolation by distance occurring at a scale probably much smaller than the mean distance between traps (this mean distance being typically 200-300 $\mathrm{m}$ in West Africa) [38]. One next challenge is to quantify reproductive dispersal and to assess why it varies so greatly from one location to the other.

\section{Second step: good molecular markers}

For population genetic studies, markers have to be sufficiently polymorphic, selectively neutral and co-dominant. Microsatellite DNA markers fulfil all these criteria and are also relatively cheap and easy to score. Other techniques such as RFLP (Restriction Fragment Length Polymorphism), MLST (Multi Locus Sequence Typing) and SSCP (Single Strand Conformation Polymorphism) can provide useful information, but are generally more expensive and/ or require more DNA quantities and are, thus, less appropriate for small organisms. Single Nucleotide Polymorphisms (SNPs) are excellent markers for association studies but not ideal population genetic markers because they display very small mutation rates, and most of them are biallelic (maximum possible homoplasy; Box 2). Markers from mtDNA require sequencing, are uniparentally inher- ited and hence represent only one sex in dioecious organisms, and are more useful for phylogenetic and/or phylogeographic studies. Furthermore they can violate neutral assumptions as demonstrated in several studies (reviewed in Ref. [14]).

However, some microsatellite loci can display technical problems such as null alleles and short allele dominance [30], which must always be investigated, and such problematic loci should ideally be removed from analyses. The good news is that with the prospect of the entire tsetse genome sequences being available shortly (http://apps. who.int/tdr/publications/about-tdr/annual-reports/vectorcontrol-interventions-2008/pdf/BL5-annual-report-2008. pdf), selecting the best markers will become a much easier task.

In recent studies, other markers than molecular ones have been used as a cheaper surrogate: this is the case of geometric morphometrics [40]. Although the information obtained will not be the same (e.g. no access to effective population size), such markers seem interesting to be developed for complementary information such as stress detection or environmental influence on tsetse populations.

\section{Last but not least: population genetics tools}

Widespread access to powerful (but relatively cheap) microcomputers and software has also contributed to the revolution in our understanding of population genetics. The wealth and complexity of analytical procedures available can be daunting. However, recent reviews of different procedures and available software [39,49] provide help for new researchers in this rapidly developing field (Box 2).**

\section{G. palpalis populations can be structured at microgeographic scales}

The life of tsetse flies is divided in two very unequal periods: one of rest and one of flying activity. Flying activity is always short (approximately half an hour per day). The level of flight is low $(\sim 0.5 \mathrm{~m})$ and the speed elevates $(5-6 \mathrm{~m} /$ s). Displacements last a few consecutive seconds or minutes, in small successive jumps (reviewed in Ref. [21]). Using a random-walk model (Box 2), morsitans flies have been estimated to have a root-mean-square displacement in one day, ranging from $167 \mathrm{~m}$ to more than $1.3 \mathrm{~km}$ [50]. This model was then adapted to a one-dimensional model accounting for riverine species of the palpalis group because of their linear movements along rivers [29]: movements of $G$. palpalis mostly occur forward and backward along the river in humid savannahs [38], but rarely out of this riverine habitat except in the rainy season when humidity is high and where flies might be able to cross from one river basin to another. It has recently been estimated, using both microsatellite DNA markers and MRR methods, that the mean dispersal distance for wild G. palpalis in Burkina Faso lies between 1245 and $2392 \mathrm{~m}$ per generation (80-1258 m using microsatellite markers) [38], which suggests that tsetse populations could recolonise an area at a rate of $7.5 \mathrm{~km} /$ year.

In many areas inhabited by G. palpalis s.l., high and significant $F_{\text {IS }}$ values were found (e.g. in Burkina Faso $[29,39,41]$; in Ivory Coast [30]). To explain this, a Wahlund 


\section{Box 4. Outstanding questions}

Question 1. Why are some tsetse able to fly for several kilometres, whereas their populations appear to be locally structured? What are the consequences of such local structuring for control?

As detailed in Ref. [51], in a four-level structure (individuals, subpopulations, archipelagos and total) where it is reasonable to assume that migration between archipelagos is not higher (and even that it is lower) than between subpopulations from the same archipelago, when differentiation is strong between subpopulations, then it will be apparently weak between higher levels. This is because most information of the apportionment of genetic information is contained in subpopulations. Biologically speaking, if migration is weak at one nested level, it is necessarily also weak between higher levels (not much supplementary information is brought by this added information). Applied to G. palpalis on its riverine habitat of the Mouhoun river in Burkina Faso, this means that local populations encompass genetically diverse flies, and that geographically disparate flies can be genetically similar [38]. Further studies on tsetse genetic structures at a local scale could help to understand why, for instance, tsetse of the palpalis group appear to have very variable responses to various stimuli such as (i) vision colours, sizes or shape of attractive systems $[52,53,54]$ and (ii) olfaction - responses to olfactory attractants $[35,49]$.

Question 2: How to infer long distance genetic structure (hence infer dispersal) when short distance structure is too high? Finding other markers than microsatellites with slower evolution might do the job. Focusing on precise information at local scale (around $100 \mathrm{~km}^{2}$ ) will facilitate our understanding of what is going on at a more global scale (typically around $10,000 \mathrm{~km}^{2}$ ).

Question 3: Does the vector host reflect the population genetics of trypanosomes? How strong is the correlation between trypanosome and tsetse population genetics? Can we measure how far tsetse represent a demographic constraint to trypanosomes? Population genetics co-structure analyses of both tsetse and the trypanosomes that they harbour should be undertaken to answer this.

effect (see definition in Box 2) was observed both in Burkina Faso for G. p. gambiensis and in Ivory Coast for G. $p$. palpalis. Microstructuring of tsetse populations into clusters or subpopulations that live in very limited areas and that are genetically differentiated from each other was observed $[29,30]$. This might appear at variance with the theoretically high dispersal capacities of tsetse and suggests that feeding dispersal outreaches reproductive (mating and larviposition) dispersal (Box 4). Local structuring might be the consequence of several factors, such as habitat fragmentation due, for instance, to vegetation destruction arising from the increased cultivation of cotton areas which strongly limits riverine tsetse movements. As an example, G. palpalis showed diffusion coefficients 8-10 times lower than that observed 20 years ago on the same river basin in Burkina Faso [37]. In addition, one-dimensional dispersal such as the one of G. p. gambiensis in riverine habitats in Burkina Faso, is known to lead to strong population structuring [16]. This local population structuring offers the opportunity to maintain high variability at fine geographic scales. Palpalis group tsetse have been reported to be much less vulnerable to high human densities than are flies of the morsitans group $[19,20]$. The phylogenetically close species $G$. fuscipes is currently responsible for the most extensive sleeping sickness epidemics in Kinshasa, Democratic Republic of Congo [11]. Could it be that the local population structuring of palpalis group flies that maintains its high genetic variability explain their ability to adapt to such different situations?

\section{Main tsetse control strategies}

There are two main strategies against tsetse populations: eradication and suppression. Genetic results will provide important insights that allow vector control programmes to assess whether eradication or suppression is appropriate. This will, in turn, determine the methods, budget, duration and human resources required [55].

\section{Eradication}

This strategy, defined by Food and Agriculture Organisation (FAO) as the creation of a tsetse-free zone [56] in the context of area-wide insect pest management principles [57], aims at totally removing a tsetse population from a given area. As a consequence, although it is not an absolute prerequisite, the targeted area (the geographic scale of which is the one of the targeted population) should be isolated (physically and, hence, genetically) from the most proximate other ones [58]. If the population is not naturally isolated from neighbouring ones, it can still be isolated artificially by setting up barriers of insecticide impregnated traps [7]. In the long run, when eradicating a population, the intervention is supposed to be applied only once, whereas suppression operations must be repeated. It is thought by some that the use of the SIT to eradicate a tsetse population would be environmentally safer and less polluting than the use of insecticides [59]. There are several different available methods that have been used for tsetse eradication in different regions of Africa, including SIT, odour-baited insecticide-treated traps and targets (for a review, see Ref. [60]) or aerial insecticide spraying in the Okavango delta of Botswana and in Namibia [61]. In West Africa, several tsetse-eradication campaigns have begun: one on Loos islands, Guinea [62]; one in the Niayes region of Senegal; and one in Burkina Faso. These vector control programmes have all requested population genetics data to be informed whether or not the target populations were genetically isolated from the neighbouring ones (see examples below).

\section{Suppression}

The aim of suppression operations is to reduce tsetse densities until there is no, or only an acceptable, transmission risk. This strategy can also be chosen if the targeted tsetse population is not, or cannot be, isolated (as indicated by, e.g. genetic analyses of the target population). These types of interventions have been applied either to HAT foci or to AAT at a small scale (e.g. livestock ranch) up to a few thousand $\mathrm{km}^{2}$; they have generally been technically successful [7,63], but not always sustainable (reviewed in Ref. [64]). However, in circumstances where eradication is impossible because of technical, financial or political considerations, then tsetse suppression seems to be the most 'reasonable' option to achieve an immediate impact on transmission.

\section{Preliminary surveys}

Preliminary surveys are mandatory for any control operation, whatever its strategy, size and procedure. In general, these surveys occur in the dry season, the year before the control phase (reviewed in Ref. [65]). They have to define the boundaries of the target tsetse population, its 
spatial distribution, density and other key parameters, such as the distribution of larviposition sites and the way to access them. These data will not only assist in the design of intervention strategies but will also provide the basis of assessing success. This survey phase is of paramount importance because any mistake (e.g. presence of flies in an area where they were thought to be absent) can undermine the success of an intervention. This is the phase where genetic data and pre-control reference material have to be collected.

\section{From population genetics to tsetse control}

In addition to establishing (i) the population structure of the targeted population and (ii) parameters such as dispersal, population sizes and spatial limits of local subpopulations, population genetics, combined with adequate precontrol reference collections and appropriate sampling strategy can determine the likely source of any re-invading flies (i.e. whether apparent re-invasions are as a result of survivors of the original population or are immigrants from untreated areas). The advent of molecular markers suitable for population genetics, such as microsatellite loci applied to tsetse $[66,67]$ assisted greatly in the recent studies on the subject. Subpopulations or demes (Box 2) that exchange flies will be much more genetically homogeneous, with similar allelic frequencies, than those between which little or no genetic exchange exists (i.e. different allele frequencies owing to a lack of gene flow) (Box 2). It is therefore desirable to collect samples for this purpose from the target area being surveyed and from neighbouring areas. Results of such analyses will confirm or contradict the assumed degree of isolation of the target population. As a recent example, populations of G. palpalis gambiensis from the Loos islands near Conakry (Guinea) were sampled together with populations from the mainland (Figure 2a). Populations from Loos were found to be small and distinct from the widely dispersed panmictic population of the nearby continental mangrove habitat $[28,40]$. This genetic information, together with field ecological observations, indicates that complete elimination of tsetse from these islands could be considered [62]. Another, different example is the one of the Mouhoun river in Burkina Faso, an area selected by PATTEC for tsetse eradication. Here a local isolation by distance was found [38] owing to dense deployment of traps along the river in a savannah landscape (Figure $2 \mathrm{~b}$ ). In this case, populations display a slow genetic diffusion even if dispersal along rivers in savannah is high between adjacent sites. Then, if elimination is chosen, artificial barriers of insecticide impregnated traps and targets must be deployed to isolate the area. Finally, another example has been illustrated in Burkina Faso, when measuring gene flow between tsetse belonging to two different but geographically close river basins (Figure 2c): the Comoe and Mouhoun basins are separated by only $2 \mathrm{~km}$ of conserved savannah at their closest distance. Here microsatellite markers did not show any differentiation between tsetse from these two basins [68]. The question remains if it is as a result of tsetse crossing from one basin to another (only a small number is required for migration to compensate the effect of genetic drift) or if the markers used are not 'sensitive' enough to

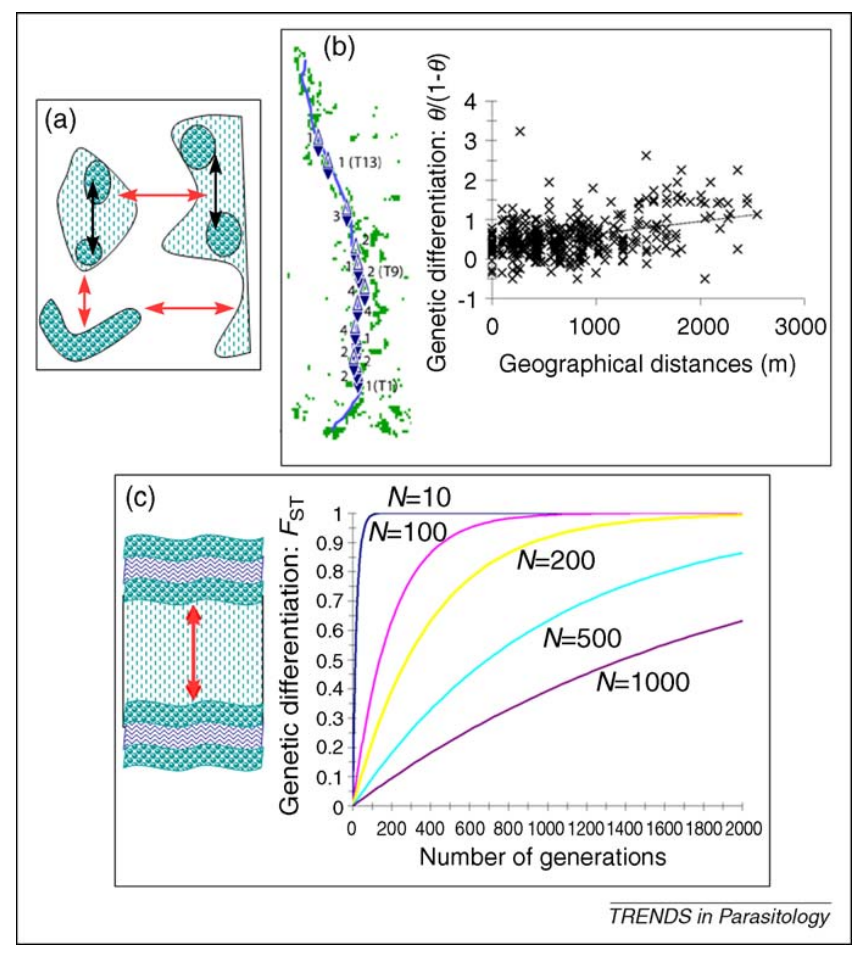

Figure 2. Different population structures in G. palpalis and implications for contro strategies. Differences in the population genetics of field-caught tsetse ( $G$. $p$. gambiensis) can suggest different tsetse control strategies. In (a), different patches where tsetse live can be sampled in either continental or island ecosystems (see example of Loos islands in Guinea in the text). In (b), isolation by distance along a river in a savannah landscape is illustrated. Detecting this requires dense deployment of traps (T) (blue biconicals) along the river (approximately one trap every $100 \mathrm{~m}$ ). An example of this situation is provided by tsetse on the Mouhoun River in Burkina Faso (see text). In (c), tsetse from two different but geographically close river basins (green dots representing savannah) were compared (see example of the Comoe and Mouhoun basins in Burkina Faso).

detect a recent isolation. This will depend on assumptions relating to population size and to time since inter-river gene flow ceased (see graph of Figure 2c).

\section{Estimating effective population sizes in G. palpalis}

In littoral Guinea, the effective population sizes found on Loos islands $\left(2<N_{e}<145\right)$ were unexpectedly far lower than the perceptible census size [28], this latter having given high apparent densities (up to 100 in some traps, with a mean of 10 flies per trap per day). These were the first estimates of effective population sizes using both temporal and spatial samples on a tsetse of the palpalis group. One of the hypotheses included a possible bottleneck owing to intense bauxite mining activity that destroyed favourable environments. This led to a higher estimate of post-bottleneck effective population size (Box 2). Nevertheless, further investigations are needed, taking into account several possible hypotheses, such as variance in reproductive success or Wahlund effect, for example. It is noteworthy that, in Dubreka (on the Guinean mainland), the inferred migration rate of $G$. palpalis was of the same magnitude as that inferred independently from T. b. gambiense isolated from patients in the same zone [5]. This suggests that G. p. gambiensis in littoral Guinea acts as a major demographic constraint (as far as dispersal is concerned at least) on $T$. b. gambiense. Such Ne estimates remain very scarce in tsetse. Along the Mouhoun river in 
Burkina Faso, G. p. gambiensis effective population sizes were also found to be relatively small (between 2 and 25 per $\mathrm{km}$, depending on the method) [38] and were probably underestimated. In Bonon (Ivory Coast), a re-analysis of the clustered data from Ravel et al. [30] suggests similar values for G. p. palpalis (between 4 and 84 per $\mathrm{km}$, depending on the method used). In East Africa, using mitochondrial markers on a savannah species of the morsitans group, very low $N e$ estimates were found for $G$. swynnertoni and were attributed to a recent bottleneck [69]. Estimating effective population sizes is undoubtedly a topic that deserves further study, because this type of information is an essential prerequisite for tsetse control monitoring, particularly post-control follow up.

\section{The future of tsetse genetics}

Population genetics is emerging as a major topic of tsetse research, providing important information of direct benefit to control programmes, particularly if eradication of vector populations is contemplated. Some donors have also taken this into account and have recently funded research or control projects where tsetse genetics constitute a significant part. It has been particularly encouraging to see that (i) genetic results using microsatellite markers converge with MRR estimates of $G$. palpalis dispersal in riverine habitats and (ii) several studies in different locations indicate a trend for G. palpalis to display very local structures, at least in environments that have been degraded by human activities. Associating population genetics with satellite imagery and geographic information systems (landscape genetics) [70] will undoubtedly become more important in the near future to facilitate control programmes. It will be of great benefit to increase the number of genetic markers, to tighten sampling meshes in zones where Wahlund effects are expected and to have additional and more accurate data on tsetse effective population sizes. The tsetse genome sequence, expected to be published soon, will be of great benefit [71], giving access to new markers, as was the case when genomes of other vectors (e.g. Anopheles gambiae, Aedes aegypti) became available [72,73]. Comparisons with trypanosome genetics to investigate population co-structures and co-evolution also undoubtedly merit further research such as studies implemented in Anopheles/Plasmodium genetics [74], as well as co-evolutions between tsetse and their symbionts [75,76]. So far, genetic studies on tsetse of the palpalis group have focused mainly on the species G. palpalis sensu lato. Research on other tsetse species of medical and economic importance is also under way ( $G$. tachinoides [77], $G$. fuscipes $[44,78])$. It is very encouraging that, in a context where WHO and PATTEC have launched pan-African trypanosomiases elimination programmes, more and more control interventions are using population genetics data to assist in designing vector control strategies.

\section{Acknowledgments}

We thank the main contributors to our research on tsetse population genetics: a European Union project, the joint FAO-International Atomic Energy Agency (IAEA) Unit, the Leverhulme Trust Tsetse Research Network (LTTRN), the French Ministry of foreign Affairs project Fonds de Solidarité Prioritaire- Recherche en Entomologie, Formation, et Stratégies de prevention (FSP-REFS), and World Health Organisation- Special
Programme for Research and Training in Tropical Diseases (WHO-TDR) for its interest. We are indebted to our West African partners, in particular the CIRDES Bobo-Dioulasso (Burkina Faso) for excellent conditions of work, the Institut Pierre Richet (Ivory Coast), the National Control Programme against HAT in Guinea, and the national PATTEC project in Burkina Faso (PCZLD). We particularly thank S.J. Torr for improvement of the manuscript, as well as the referees and the Editor. P.S. and T.D.M. thank Dji Andbi and Albert Lour for their strong support.

\section{References}

1 Budd, L. (1999) Economic analysis. In DFID-Funded Tsetse and Trypanosomiasis Research and Development since 1980. Chatham, UK, Department for International Development: Livestock Production Programme, Animal Health Programme/Natural Resources Systems Programme

2 Courtin, F. et al. (2008) Sleeping sickness in West Africa (1906-2006): changes in spatial repartition and lessons from the past. Trop. Med. Int. Health 13, 1-11

3 Simarro, P.P. et al. (2008) Eliminating human African Trypanosomiasis: where do we stand and what comes next? PLoS Med. 5, e55, 174-180

4 Kabayo, J.P. (2002) Aiming to eliminate tsetse from Africa. Trends Parasitol. 18, 473-475

5 Koffi, M. et al. (2009) Population genetics of T. brucei gambiense, the agent of sleeping sickness in West Africa. Proc. Natl. Acad. Sci. U. S. A. 106, 209-214

6 Rogers, D.J. (1979) Tsetse population dynamics and distribution: a new analytical approach. J. Anim. Ecol. 48, 825-849

7 Laveissière, C. and Penchenier, L. (2005) Manuel de Lutte Contre la Maladie du Sommeil, IRD Editions, Collection Didactiques. [In French]

8 Guengant, J.P. (2007) La démographie africaine entre convergences et divergences. In L'Afrique Face à ses Défis Démographiques: Un Avenir Incertain (Ferry, B., ed.), pp. 27-121, AFD-CEPED-Karthala. [In French]

9 D’Orgeval, T. (2008) Impact du changement climatique sur la saison des pluies en Afrique de l'Ouest: que nous disent les modèles de climat actuels? Sécheresse 19, 79-85 [In French]

10 Courtin, F. et al. (2009) Impacts observés des évolutions démoclimatiques sur la répartition spatiale des hommes, des tsé-tsé et des trypanosomoses en Afrique de l'Ouest. Parasite 16, 3-10. [In French]

11 Sumbu, J. et al. (2009) Variation spatiale du risque pour les porcs de contracter la trypanosomose dans la zone périurbaine de Kinshasa. Parasite 16, 153-159 [In French]

12 Prugnolle, F. et al. (2002) Sex-specific genetic structure in Schistosoma mansoni: evolutionary and epidemiological implications. Mol. Ecol. 11, 1231-1238

13 Criscione, C.D. and Blouin, M.S. (2005) Effective sizes of macroparasite populations: a conceptual model. Trends Parasitol. 21, 212-217

14 De Meeûs, T. et al. (2007) Population genetics and molecular epidemiology or how to "débusquer la bête". Infect. Genet. Evol. 7, 308-332

15 Slatkin, M. (1987) Gene flow and the geographic structure of natural populations. Science 236, 787-792

16 Watts, P.C. et al. (2007) Compatible genetic and ecological estimates of dispersal rates in insect (Coenagrion mercuriale: Odonata: Zygoptera) populations: analysis of 'neighbourhood size' using a more precise estimator. Mol. Ecol. 16, 737-751

17 Krafsur, E.S. (2009) Tsetse flies: genetics, evolution, and role as vectors. Infect. Genet. Evol. 9, 124-141

18 Gooding, R.H. and Krafsur, E.S. (2005) Tsetse genetics: contributions to biology, systematics, and control of tsetse flies. Annu. Rev. Entomol. 50, 101-123

19 Reid, S.R. et al. (2000) Human population growth and the extinction of the tsetse fly. Agric. Ecosyst. Environ. 77, 227-236

20 Rayaisse, J.B. et al. (2009) Influence de l'anthropisation sur la végétation et l'abondance des tsé-tsé au sud du Burkina-Faso. Parasite 16, 21-28 [In French]

21 Solano P. et al. Cyclical vectors of Trypanosomosis. In Infectious and Parasitic Diseases of Livestock (Lefèvre, P.C. et al., eds.), Lavoisier Tec\&Doc. (in press)

22 Hargrove, J.W. (1988) Tsetse: the limits to population growth. Med. Vet. Entomol. 2, 203-217 
23 Bouyer, J. et al. (2007) Learning influences host choice in tsetse. Biol. Lett. 3, 113-116

24 Kubi, C. et al. (2006) The effect of starvation on the susceptibility of teneral and non teneral tsetse flies to trypanosome infection. Med. Vet. Entomol. 20, 388-392

25 Gingrich, J.B. et al. (1982) African sleeping sickness: new evidence that mature tsetse flies (Glossina morsitans) can become potent vectors. Trans. R. Soc. Trop. Med. Hyg. 76, 479-481

26 Gooding, R.H. (1988) Infection of post-teneral tsetse flies (Glossina morsitans morsitans and Glossina morsitans centralis) with Trypanosoma brucei brucei. Can. J. Zool. 66, 1289-1292

27 Challier, A. et al. (1983) La limite géographique entre les sous-espèces Glossina palpalis palpalis (Rob.-Desv.) et Glossina palpalis gambiensis Vanderplanck en Afrique occidentale. Cah. O.R.S.T.O.M. Sér Entomol. Méd. Parasitol. 21, 207-220 [In French]

28 Solano, P.et al. (2009) Population structures of insular and continental Glossina palpalis gambiensis in Littoral Guinea. PLoS Negl. Trop. Dis. 3 (3), e392 DOI: 10.1371/journal.pntd.0000392

29 Solano, P. et al. (2000) Microsatellite DNA markers reveal genetic differentiation among populations of Glossina palpalis gambiensis collected in the agropastoral zone of Sideradougou, Burkina Faso. Insect Mol. Biol. 9, 433-439

30 Ravel, S. et al. (2007) Different genetic groups occur within Glossina palpalis palpalis in the sleeping sickness focus of Bonon, Côte d'Ivoire. Infect. Genet. Evol. 7, 116-125

31 Gooding, R.H. (1997) Genetic analysis of hybrid sterility in crosses of the tsetse flies Glossina palpalis palpalis and Glossina palpalis gambiensis (Diptera: Glossinidae). Can. J. Zool. 75, 1109-1117

32 Dyer, N.A. et al. (2008) Molecular phylogenetics of tsetse flies (Diptera: Glossinidae) based on mitochondrial (CO1, 16S, ND2) and nuclear ribosomal DNA sequences, with an emphasis on the palpalis group. Mol. Phylogenet. Evol. 49, 227-239

33 Gooding, R.H. et al. (2004) X chromosome mapping experiments suggest occurrence of cryptic species in the tsetse fly, Glossina palpalis palpalis (Diptera: Glossinidae). Can. J. Zool. 82, 1902-1909

34 Dyer, N.A. et al. (2009) Evidence for a discrete evolutionary lineage within Equatorial Guinea suggests that the tsetse fly Glossina palpalis palpalis exists as a species complex. Mol. Ecol. 18, 3268-3282

35 Torr, S.J. and Solano, P. Olfaction in tsetse hosts interactions. In Olfaction in Vector Hosts Interactions (Knols, B. and Takken, W., eds), Wageningen University (in press)

36 Balloux, F. (2004) Heterozygote excess in small populations and the heterozygote-excess effective population size. Evolution 58, 1891-1900

37 Bouyer, J. et al. (2007) A diffusion model for Glossina palpalis gambiensis in Burkina Faso. In Area-wide Control of Insect Pests From Research to Field Implementation (Vreysen, M.J.B. and et, al., eds), pp. 221-228, Springer

38 Bouyer, J. et al. (2009) Population sizes and dispersal pattern of tsetse flies: rolling on the river? Mol. Ecol. 18, 2787-2797

39 De Meeûs, T. and Goudet, J. (2007) A step-by-step tutorial to use HierFstat to analyse populations hierarchically structured at multiple levels. Infect. Genet. Evol. 7, 731-735

40 Camara, M. et al. (2006) Genetic and morphometric evidence for population isolation of Glossina palpalis gambiensis from Loos islands, Guinea. J. Med. Entomol. 43, 853-860

41 Solano, P. et al. (1999) Intraspecific variability in natural populations of Glossina palpalis gambiensis from West Africa, revealed by genetic and morphometric analyses. Med. Vet. Entomol. 13, 401-407

42 Ouma, J.O. et al. (2006) Microgeographical breeding structure of the tsetse fly, Glossina pallidipes in south-western Kenya. Med. Vet. Entomol. 20, 138-149

43 Ouma, J.O. et al. (2007) Patterns of genetic diversity and differentiation in the tsetse fly Glossina morsitans morsitans Westwood populations in East and southern Africa. Genetica 130, 139-151

44 Abila, P.P. et al. (2008) High levels of genetic differentiation between Ugandan Glossina fuscipes fuscipes populations separated by Lake Kyoga. PLoS Negl. Trop. Dis. 2, e242

45 Holm, S. (1979) A simple sequentially rejective multiple test procedure. Scand. J. Stat. 6, 65-70

46 Goudet, J. (1995) FSTAT (version 1.2): a computer program to calculate F-statistics. J. Hered. 86, 485-486
47 Rousset, F. (2008) GENEPOP' 007: a complete re-implementation of the GENEPOP software for Windows and Linux. Mol. Ecol. Resources 8, 103-106

48 Teriokhin, A.T. et al. (2007) On the power of some binomial modifications of the Bonferroni multiple test. Zh. Obshch. Biol. 68, $332-340$

49 Excoffier, L. and Heckel, G. (2006) Computer programs for population genetics data analysis: a survival guide. Nat. Rev. Genet. 7, 745-758

50 Williams, B. et al. (1992) The control of tsetse flies in relation to fly movement and trapping efficiency. J. Appl. Biol. 29, 163-179

51 Rougeron, V. et al. (2009) Extreme inbreeding in Leishmania braziliensis. Proc. Natl. Acad. Sci. U. S. A. 106, 10224-10229

52 Laveissière, C. et al. (1987) Recherche sur les écrans pour la lutte contre les glossines en zone forestière de Côte d'Ivoire. Mise au point d'un nouvel écran. Cah. ORSTOM sér. Ent. Méd. Parasitol. 25, 145164. [In French]

53 Lindh, J.M. et al. (2009) Improving the cost-effectiveness of artificial visual baits for controlling the tsetse fly Glossina fuscipes fuscipes. Plos Negl. Trop. Dis. 3, e474

54 Omolo, M.O.et al. (2009) Prospects for developing odour baits to control Glossina fuscipes spp., the major vector of human African trypanosomiasis. PLoS Negl. Trop. Dis. 3, e435

55 Schofield, C.J. and Kabayo, J. (2008) Trypanosomiasis vector control in Africa and Latin America. Parasit. Vectors 1, 24

56 Food and Agriculture Organization of the United Nations (2005) Glossary of Phytosanitary Terms. ISPM, Publication Number 5, International Plant Protection Convention (IPPC), FAO

57 Hendrichs, J. et al. (2005) Strategic options in using sterile insects for area-wide integrated pest management. In Sterile Insect Technique. Principles and Practice in Area Wide Integrated Pest Management (Dyck, V.A. et al., eds), pp. 563-600, Springer

58 Vreysen, M.J.B. (2005) Monitoring sterile and wild insects in area wide integrated pest management programmes. In Sterile Insect Technique. Principles and Practice in Area Wide Integrated Pest Management (Dyck, V.A. et al., eds), pp. 325-361, Springer

59 Vreysen, M.J.B. et al. (2000) The use of the sterile insect technique (SIT) for the eradication of the tsetse fly Glossina austeni on the island of Unguja (Zanzibar). J. Econ. Entomol. 93, 123-135

60 Hargrove, J.W. (2003) Tsetse Eradication: Sufficiency, Necessity and Desirability (DFID Animal Health Programme, eds), Centre for Tropical Veterinary Medicine, University of Edinburgh

61 Kgori, P.M. et al. (2006) The use of aerial spraying to eliminate tsetse from the Okavango Delta of Botswana. Acta Trop. 99, 184-199

62 Kagbadouno, M. et al. (2009) Tsetse elimination: its interest and feasibility in the historical sleeping sickness focus of Loos islands. Guinea. Parasite 16, 29-36

63 Bauer, B. et al. (1999) Improvement of cattle productivity through rapid alleviation of African animal Trypanosomosis by integrated disease management practices in the agropastoral zone of Yalé, Burkina Faso. Trop. Anim. Health Prod. 31, 89-102

64 Kuzoe, F.A.S. and Schofield, C.J. (2005) Strategic Review of Traps and Targets for Tsetse and African Trypanosomiasis Control. TDR/IDE/ TRY/05.1, $58 \mathrm{pp}$

65 Bouyer, J. et al. Trypanosomoses: control methods. In Infectious and Parasitic Diseases of Livestock (Lefèvre, P.C. et al., eds), Lavoisier Tec\&Doc (in press)

66 Solano, P. et al. (1997) Microsatellite markers for genetic population studies in Glossina palpalis (Diptera: Glossinidae). Acta Trop. 65, $175-180$

67 Luna, C. et al. (2001) Microsatellite polymorphism in tsetse flies. $J$ Med. Entomol. 38, 376-381

68 Bouyer, J. et al. (2010) Population structure of Glossina palpalis gambiensis (Diptera: Glossinidae) between river basins in BurkinaFaso: consequences for area-wide integrated pest management. Infect. Genet. Evol. 10, 321-328

69 Marquez, J.G. et al. (2006) Glossina swynnertoni (Diptera: Glossinidae): effective population size and breeding structure estimated by mitochondrial diversity. Bull. Entomol. Res. 96, 353-360

70 Storfer, A. et al. (2007) Putting the landscape in "landscape genetics". Heredity 98, 128-142

71 Aksoy, S. et al. (2005) A case for a Glossina genome project. Trends Parasitol. 21, 107-111 
72 Holt, R.A. et al. (2002) The genome sequence of the malaria mosquito Anopheles gambiae. Science 298, 129-149

73 Nene, V. et al. (2007) Genome sequence of Aedes aegypti, a major arbovirus vector. Science $316,1718-1723$

74 Annan, Z. et al. (2007) Population genetic structure of Plasmodium falciparum in the two main African vectors Anopheles gambiae and Anopheles funestus. Proc. Natl. Acad. Sci. U. S. A. 104, 7987-7992

75 Aksoy, S. et al. (2008) Paratransgenesis applied for control of tsetse transmitted sleeping sickness. Adv. Exp. Med. Biol. 627, 35-48
76 Farikou, O. et al. (2010) Tripartite interactions between tsetse flies, Sodalis glossinidius and trypanosomes - an epidemiological approach in two historical human African trypanosomiasis foci in Cameroon. Infect. Genet. Evol. 10, 115-121

77 Kone, N. et al. (2010) Population structuring of the tsetse Glossina tachinoides resulting from landscape fragmentation in the Mouhoun River Basin, Burkina Faso. Med. Vet. Entomol. DOI: 10.1111/j.13652915.2010.00857.x

78 Krafsur, E.S. et al. (2008) Structure of some East African Glossina fuscipes fuscipes populations. Med. Vet. Entomol. 22, 222-227 